\title{
Effects of ventricular entry on patient outcome during glioblastoma resection
}

\author{
*Jacob S. Young, MD, ${ }^{1}$ Andrew J. Gogos, MBBS, ${ }^{1}$ Matheus P. Pereira, BS, ${ }^{2}$ Ramin A. Morshed, MD, ${ }^{1}$ \\ Jing Li, MD, ${ }^{1}$ Matthew J. Barkovich, MD, ${ }^{3}$ Shawn L. Hervey-Jumper, MD, ${ }^{1}$ and \\ Mitchel S. Berger, MD ${ }^{1}$
}

${ }^{1}$ Department of Neurological Surgery, ${ }^{2}$ School of Medicine, and ${ }^{3}$ Department of Radiology and Biomedical Imaging, University of California, San Francisco, California

OBJECTIVE Tumor proximity to the ventricle and ventricular entry (VE) during surgery have both been associated with worse prognoses; however, the interaction between these two factors is poorly understood. Given the benefit of maximal tumor resection, it is imperative for surgical planning and technique to know if VE has negative consequences for patient survival and tumor dissemination.

METHODS The University of California, San Francisco tumor registry was searched for patients with newly diagnosed and recurrent supratentorial glioblastoma (GBM) who underwent resection by the senior author between 2013 and 2018. Tumor location with respect to the subventricular zone (SVZ), size, and extent of resection were assessed using pre- and postoperative imaging. VE was determined by postoperative imaging and/or the operative report.

RESULTS In this 200-patient cohort of newly diagnosed and recurrent GBM, 26.5\% of patients had VE during resection. Patients with VE were more likely to have preexisting subependymal disease $(41.5 \%$ vs $15.0 \%, p<0.001)$. Comparing patients with VE to those without VE, there was no difference in the rates of postoperative hydrocephalus $(1.9 \%$ vs $4.8 \%, p=0.36)$, ventriculoperitoneal shunting ( $0 \%$ vs $3.4 \%, p=0.17)$, pseudomeningoceles $(7.5 \%$ vs $5.4 \%, p=0.58)$, or subdural hematomas $(11.3 \%$ vs $3.4 \%, p=0.07)$. Importantly, rates of subsequent leptomeningeal disease $(7.5 \%$ vs $10.2 \%, p=0.57)$ and distant parenchymal recurrence $(17.0 \%$ vs $23.1 \%, p=0.35)$ were not different between the groups. Newly diagnosed patients with tumors contacting the SVZ (type I or II) had worse survival than patients with tumors that did not contact the SVZ (type III or IV) (1.27 vs 1.84 years, $p=0.014, \mathrm{HR} 1.8,95 \% \mathrm{Cl} 1.08-3.03$ ), but VE was not associated with worse survival in these patients with high-risk SVZ type I and II tumors (1.15 vs 1.68 years, $p=0.151, H R$ 0.59, $95 \% \mathrm{Cl}$ 0.26-1.34).

CONCLUSIONS VE was well tolerated, with postoperative complications being rare events. There was no increase in leptomeningeal spread or distant parenchymal recurrence in patients with VE. Finally, although survival was worse for patients with preoperative subependymal disease, VE did not change survival for patients with tumors contacting the ventricle. Therefore, VE during GBM resection is not associated with adverse patient outcomes and should be used by surgeons to enhance extent of resection.

- CLASSIFICATION OF EVIDENCE Type of question: therapeutic; study design: retrospective cohort; evidence: class II.

https://thejns.org/doi/abs/10.3171/2020.7.JNS201362

KEYWORDS ventricular entry; glioblastoma; subventricular zone; subependymal disease; leptomeningeal spread; oncology

$\mathrm{D}$ ESPITE an improved understanding of glioblastoma (GBM) biology and advances in surgical technique for tumor resection, the prognosis for patients remains poor. ${ }^{1,2}$ Certain tumor characteristics, such as large size and deep location, are associated with worse patient survival. ${ }^{3}$ For example, insular tumors, bihemispheric le- sions crossing the corpus callosum, and periventricular masses have all been associated with worse survival, which may be related to the close relationship these tumors have with vital vascular structures and eloquent brain tissue, as well as the surgical challenge associated with achieving a maximal resection. ${ }^{4-6}$

ABBREVIATIONS EOR = extent of resection; GBM = glioblastoma; KPS = Karnofsky Performance Scale; SVZ = subventricular zone; UCSF = University of California, San Francisco; VE = ventricular entry.

SUBMITTED April 19, 2020. ACCEPTED July 29, 2020.

INCLUDE WHEN CITING Published online January 8, 2021; DOI: 10.3171/2020.7.JNS201362.

${ }^{*}$ J.S.Y. and A.J.G. contributed equally to this work. 


\section{- CLASSIFICATION OF EVIDENCE}

\section{TYPE OF QUESTION Therapeutic}

\section{STUDY DESIGN Retrospective cohort \\ EVIDENCE Class II}

\section{Summary Statement}

This class II study suggests, contrary to the results of a recent meta-analysis, that ventricular entry (VE) during resection of newly diagnosed or recurrent glioblastomas is not associated with shorter survival, leptomeningeal dissemination of tumor, or distant recurrences.

\section{Classification of Evidence}

Young and colleagues have provided a valuable service to the neurosurgical community by addressing, in a meticulously analyzed single-center study, the question of whether VE during glioblastoma resection results in more frequent leptomeningeal dissemination of tumor, more frequent distant recurrences, and shorter overall survival. The authors found no differences in any of these important endpoints in patients with either newly diagnosed or recurrent disease, or in both groups combined. The authors acknowledge that the retrospective, nonrandomized nature of their study conveys a moderate risk of bias. In their favor, the primary endpoint-overall survivalis objective and relatively resistant to outcome assessment bias, although this is less true for the other study endpoints (leptomeningeal dissemination, distant recurrence) and for some potential predictors (extent of resection, Karnofsky Performance Scale score, subventricular zone type). In addition, although there were no statistically significant differences in patient characteristics between the VE and no-VE groups for the entire 200-patient cohort (Table 1), patients with VE were less likely to receive postoperative chemotherapy ( $83 \%$ vs $98 \%$ ) and radiation ( $81 \%$ vs $98 \%$ ), and less likely to undergo a gross-total resection (32.1\% vs $46.9 \%$ ). These differences might be clinically important and hint at the possibility of other uncharacterized or unrecognized differences between groups, including surgeon judgment, which may be present. Unfortunately, the authors do not provide data regarding the distribution of potentially prognostically important characteristics for the newly diagnosed patient group alone $(n=111$ patients), the group on which, for good statistical reasons, the authors focus their attention. A look at the quantitative results of the primary endpoint analysis-overall survival-is particularly instructive and leads to the question: what is the appropriate measure of effect in time-to-event studies? The most common measure of effect in such studies is the hazard ratio (HR), which is the chance of an outcome-in this case death-occurring in one group (say the VE group) compared to (divided by) another group (the no-VE cohort). The HR conveys with a single number the distance between the individual Kaplan-Meier curves of the two groups over the entire time period of the study. Because the HR is a relative measure of outcome, good studies (like this one) also provide a more absolute measure of outcome, often (as with this study) median survival (1.22 vs 1.75 years). One can see from this example that for Kaplan-Meier curves depicting survival, HRs greater than 1 describe a worse outcome, and HRs less than 1 describe a better outcome for the group of interest compared to the control. This is depicted visually in Fig. 3A, where the blue curve (no VE) is roughly parallel to and lies above the red curve (VE) over the entire interval of the study. Turning to the numbers, in the authors' univariate analysis of survival, the presence of subependymal disease (HR 2.0 [95\% $\mathrm{Cl} 1.01-3.95], p=0.046$ ) was a statistically significant predictor, and VE (HR 1.72 [95\% Cl 0.93-3.17], $p=0.083)$ approached statistical significance. In the multivariate analysis (also referred to as a Cox proportional hazards analysis), which controls for the effect of potential confounders, both putative predictors of survival lose their statistical significance: for subependymal disease, HR $1.87(95 \% \mathrm{Cl} 0.94-3.72, \mathrm{p}$ $=0.075)$; and for VE, HR 1.61 (95\% Cl 0.86-2.99, $p=0.13$ ). Unfortunately, the wide $\mathrm{Cls}$ render solid conclusions unlikely. In other words, the estimate of effect is too imprecise given the small sample size. Far from negating the value of the authors' study, however, this discrepancy suggests that we do not yet have a definitive answer. There may be subsets of patients and specific circumstances in which VE does not convey increased risk and shortened survival. In the absence of a randomized trial, the current study, taken in context with preceding similar studies, suggests that additional, larger, carefully designed, prospective trials are essential. In the meantime, clinicians must, as always, base their treatment decisions on experience, judgment, and patient values as well as on data.

- Michael Glantz, MD
Hershey Medical Center
Hershey, Pennsylvania

For tumors with a periventricular location, prior work has suggested that patients with lesions bordering the lateral ventricles are more likely to present with multifocal disease and to have decreased survival compared to patients with tumors that do not border the ventricular system. ${ }^{4,7}$ Additionally, the subventricular zone (SVZ), which is the region bordering the lateral ventricle, is a known pluripotent stem cell niche in the adult CNS. ${ }^{8,9}$ As such, it may play an important role in the development of GBM, and tumor proximity to the SVZ may portend a worse prognosis independent of the surgical risks associated with removing the lesion.

Relatively little is known about the importance of ventricular entry (VE) during periventricular tumor resection. Reports vary on the potential role VE plays in facilitating tumor dissemination, and thus whether it negatively impacts patient survival. One report found that entering the ventricle during tumor resection was associated with a significantly higher rate of perioperative complications, with nearly half of patients developing a complication if the ventricle was entered. ${ }^{10}$ In that study, patients with VE were more likely to develop hydrocephalus, intraventricular hemorrhage, or postoperative infection, and subsequently to require a ventriculoperitoneal shunt. Moreover, a recent meta-analysis also found that VE during glioma surgery was associated with a higher rate of hydrocephalus, leptomeningeal dissemination, and decreased patient survival. ${ }^{11}$ This perceived increased surgical risk may cause surgeons to avoid VE and to compromise extent of tumor resection. 

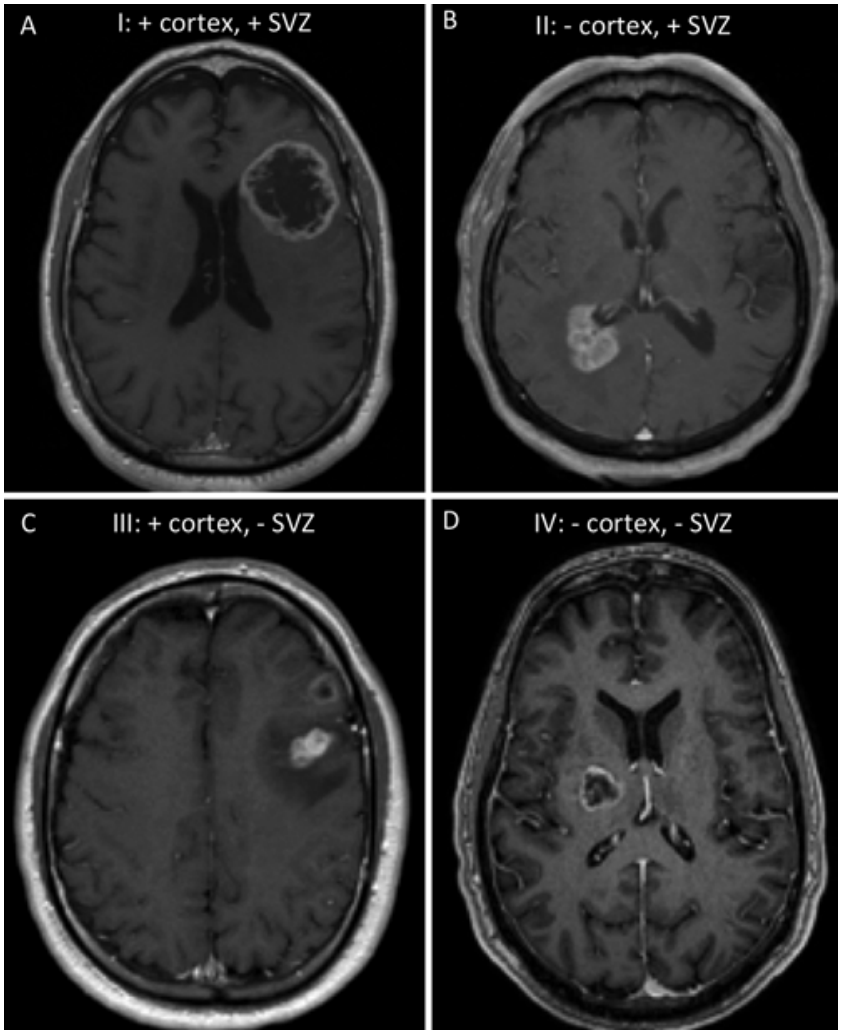

FIG. 1. Representative examples of the different SVZ tumor types. A: SVZ type I: contrast-enhancing tumor spans from the ventricular edge to the cortical gray matter. B: SVZ type II: contrast-enhancing tumor contacts the ventricular edge but does not contact the cortical gray matter. C: SVZ type III: contrast-enhancing tumor contacts the cortical surface but not the ventricular wall. D: SVZ type IV: contrast-enhancing tumor does not contact the ventricular wall or the cortical gray matter.

However, other authors have found that subventricular tumor location, and not operative entry into the ventricle, is actually what leads to worse outcomes for these patients. ${ }^{12}$ Given these incongruent findings, we set out to determine the effects of VE on survival, distant tumor recurrence, leptomeningeal disease, and complications for patients who undergo resection of GBM. We hypothesized that tumor location, rather than VE, would be associated with worse prognosis and leptomeningeal spread.

\section{Methods}

\section{Patient Selection and Characteristics}

After obtaining approval from the University of California, San Francisco (UCSF) institutional review board, the UCSF tumor registry was searched for patients who underwent resection for supratentorial GBM (WHO grade IV) by the senior author between 2013 and 2018, and in whom all the necessary pre- and postoperative images were available. Patient, tumor, and outcome data were collected retrospectively from operative, radiology, pathology, and scanned documents available through the UCSF electronic medical record. We chose to review the senior author's cases from 2013 to 2018 because we thought that
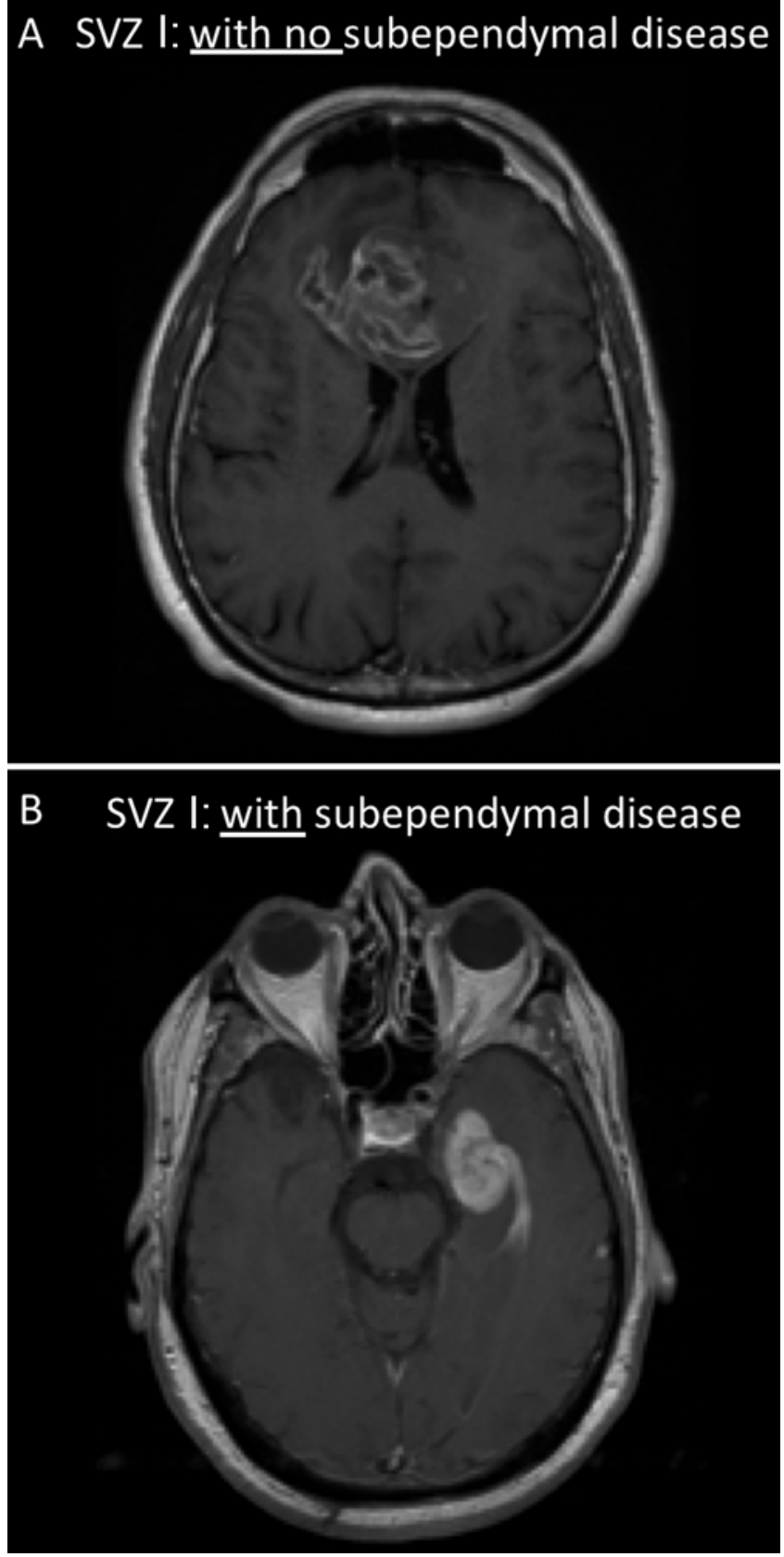

FIG. 2. Representative examples of presence and absence of preoperative subependymal disease. A: Example of SVZ type I tumor without preoperative imaging evidence of subependymal disease. B: Example of SVZ type I tumor with preoperative imaging evidence of subependymal disease.

this cohort provided a homogeneous sample with optimal imaging quality and adequate follow-up time to answer our hypothesis.

\section{Assessment of VE and Tumor Location}

VE was determined by documentation in the surgeon's operative note and/or by a visible communication between the resection cavity and ventricle on the postoperative MRI. At the time of VE, nothing was used to seal the 
TABLE 1. Patient and tumor characteristics in 200 patients with GBM

\begin{tabular}{|c|c|c|c|c|}
\hline Patient or Tumor Characteristic & Overall & VE & No VE & $\mathrm{p}$ Value \\
\hline No. of patients & 200 & $53(26.5 \%)$ & $147(73.5 \%)$ & \\
\hline Age in yrs, median & 58.00 & 60.00 & 56.00 & 0.202 \\
\hline Sex & & & & 0.163 \\
\hline Male & $112(56.0 \%)$ & $34(64.2 \%)$ & $78(53.1 \%)$ & \\
\hline Female & $88(44.0 \%)$ & $19(35.8 \%)$ & $69(46.9 \%)$ & \\
\hline LOS in days, median & 3 & 3 & 3 & 0.507 \\
\hline Avg follow-up time in mos & 18.24 & 14.19 & 19.70 & 0.028 \\
\hline Preop KPS score, median (range) & $90(40-100)$ & $90(60-100)$ & $90(40-100)$ & 0.833 \\
\hline Postop KPS score, median (range) & $80(40-100)$ & $80(50-100)$ & $80(40-100)$ & 0.666 \\
\hline Received chemotherapy & $188(94.0 \%)$ & $44(83.0 \%)$ & $144(98.0 \%)$ & 0.555 \\
\hline Received radiation & $187(93.5 \%)$ & $43(81.0 \%)$ & $144(98.0 \%)$ & 0.412 \\
\hline EOR & & & & 0.173 \\
\hline STR & $60(30.0 \%)$ & $19(35.8 \%)$ & $41(27.9 \%)$ & \\
\hline NTR & $54(27.0 \%)$ & $17(32.1 \%)$ & $37(25.2 \%)$ & \\
\hline GTR & $86(43.0 \%)$ & $17(32.1 \%)$ & $69(46.9 \%)$ & \\
\hline Prior resection & $89(44.5 \%)$ & $30(56.6 \%)$ & $59(40.1 \%)$ & 0.039 \\
\hline Future reop & $33(16.5 \%)$ & $4(7.5 \%)$ & $29(19.7 \%)$ & 0.051 \\
\hline Mean tumor vol in $\mathrm{cm}^{3}$ & 25.1 & 32.0 & 23.3 & 0.188 \\
\hline IDH1/2 wild type & $169(84.5 \%)$ & $45(84.9 \%)$ & $124(84.4 \%)$ & 0.92 \\
\hline Subependymal involvement & $44(22.0 \%)$ & $22(41.5 \%)$ & $22(15.0 \%)$ & $<0.001$ \\
\hline SVZ type & & & & $<0.001$ \\
\hline I & $78(39.0 \%)$ & $35(66.0 \%)$ & $43(29.3 \%)$ & \\
\hline II & $13(6.5 \%)$ & $7(13.2 \%)$ & $6(4.1 \%)$ & \\
\hline III & $98(49.0 \%)$ & $8(15.1 \%)$ & $90(61.2 \%)$ & \\
\hline IV & $11(5.5 \%)$ & $3(5.7 \%)$ & $8(5.4 \%)$ & \\
\hline
\end{tabular}

Avg = average; GTR = gross-total resection; IDH = isocitrate dehydrogenase; $L O S=$ length of stay; NTR = near-total resection; STR = subtotal resection.

Boldface type indicates statistical significance.

breach in the ventricular wall, and tumor resection and closure were carried out in the usual fashion. If the resection cavity was thought to be excessively bloody by the senior author, which was very infrequent, then a drain was left in the resection cavity and removed when the output cleared. Tumor location was categorized using schema described by Lim et al.: type I tumors contact both the SVZ and the cortex; type II tumors involve only the SVZ; type III tumors involve only cortex; and type IV do not contact either the SVZ or cortex (Fig. 1). Tumors were classified

TABLE 2. Outcomes following VE during GBM resection

\begin{tabular}{llcc}
\hline \multicolumn{1}{c}{ Outcome } & \multicolumn{1}{c}{ VE } & No VE & p Value \\
\hline Leptomeningeal spread & $4(7.5 \%)$ & $15(10.2 \%)$ & 0.572 \\
\hline Distant parenchymal recurrence & $9(17.0 \%)$ & $34(23.1 \%)$ & 0.35 \\
\hline Postop hydrocephalus & $1(1.9 \%)$ & $7(4.8 \%)$ & 0.36 \\
\hline Need for VP shunt & $0(0 \%)$ & $5(3.4 \%)$ & 0.174 \\
\hline Cavity drain used & $6(11.3 \%)$ & $0(0 \%)$ & $<0.001$ \\
\hline Surgical site infection & $2(3.8 \%)$ & $3(2.0 \%)$ & 0.488 \\
\hline Subdural fluid collection* & $6(11.3 \%)$ & $5(3.4 \%)$ & 0.071 \\
\hline Intraventricular hemorrhage & $1(1.9 \%)$ & $2(1.4 \%)$ & 0.787 \\
\hline Pseudomeningocele & $4(7.5 \%)$ & $8(5.4 \%)$ & 0.58 \\
\hline
\end{tabular}

$\mathrm{VP}=$ ventriculoperitoneal.

Boldface type indicates statistical significance.

${ }^{*}$ No patients required evacuation of the subdural fluid collections. 
TABLE 3. EOR by SVZ type and VE for newly diagnosed patients

\begin{tabular}{|c|c|c|c|c|c|c|c|c|c|c|c|c|}
\hline & \multicolumn{3}{|c|}{ SVZ Type I } & \multicolumn{3}{|c|}{ SVZ Type II } & \multicolumn{3}{|c|}{ SVZ Type III } & \multicolumn{3}{|c|}{ SVZ Type IV } \\
\hline & VE & No VE & p Value & VE & No VE & p Value & VE & No VE & p Value & VE & No VE & $p$ Value \\
\hline EOR & $88.7 \%$ & $93.9 \%$ & 0.23 & $76.9 \%$ & $72.2 \%$ & 0.88 & $92.4 \%$ & $95.3 \%$ & 0.61 & $99.8 \%$ & $69.8 \%$ & 0.18 \\
\hline
\end{tabular}

by a neuroradiologist (M.J.B.) as involving the SVZ if the contrast-enhancing lesion contacted the ventricular ependyma. Similarly, tumors were classified as involving cortex if the contrast-enhancing lesion contacted the cortex. Patterns of recurrence were evaluated and considered to involve remote sites if the recurrent contrast-enhancing tumor was not contiguous with the resection cavity or residual tumor. To be considered a tumor with subependymal disease, there must have been significant enhancement or enhancing nodularity of the ventricular lining extending beyond mere contact with the ventricle, and as such not every SVZ type I and II tumor was considered positive for subependymal disease (Fig. 2). The extent of nonenhancing FLAIR signal abnormality was not considered when evaluated during the classification of tumor location because the FLAIR signal is more heterogeneous and may reflect edema or tumor cells.

\section{Volumetric Analysis and Quantification of Extent of Resection}

Preoperative and postoperative tumor volumes were quantified by using Brainlab Smartbrush software (Brainlab). Manual segmentation was performed with region of interest analysis based on T1-weighted postgadolinium sequences from pre- and postoperative MRI scans. The extent of resection (EOR) was calculated as follows: (preoperative tumor volume - postoperative tumor volume)/ preoperative tumor volume $\times 100 \%$. Manual segmentations were performed by three surgeons (J.S.Y., R.A.M., and J.L.). Preoperative MRI scans were obtained within 24 hours of resection, and postoperative scans were all obtained within 48 hours.

\section{A}

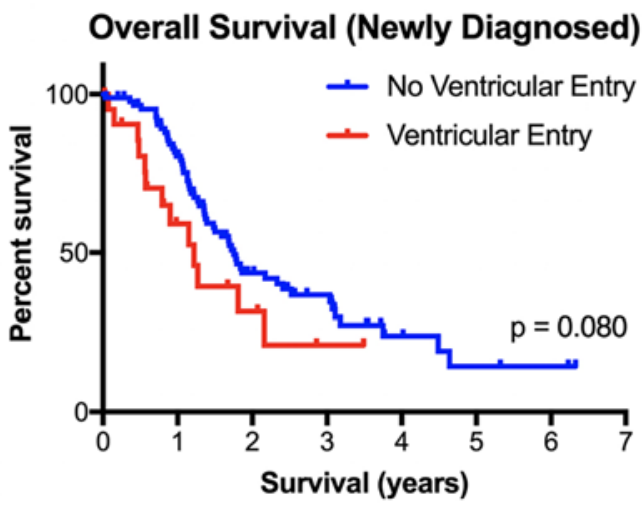

No. at Risk

$\begin{array}{lllllllll}\text { No Ventricular Entry } & 81 & 64 & 28 & 18 & 7 & 4 & 3 & 0\end{array}$ Ventricular Entry

$\begin{array}{rrrrrrrr}81 & 64 & 28 & 18 & 7 & 4 & 3 & 0 \\ 17 & 10 & 5 & 2 & 0 & 0 & 0 & 0\end{array}$

\section{Statistical Analyses}

Descriptive statistics were used to define the patient cohort, tumor characteristics, treatment details, and neurological outcomes. Student t-test, uni- and multivariate regression analyses, chi-square tests, and Fisher exact tests were used to assess for differences between cohorts. Variables with $p$ values less than 0.2 in the univariate analysis were included in the multivariate analysis. Overall survival was calculated from the date of surgery until death or the end of follow-up. The median overall survival was computed using the Kaplan-Meier method and Cox proportional hazards model. The level of significance was 0.05 for all analyses. Statistical analysis was performed using JMP Pro 14 (SAS Institute), and GraphPad Prism 7.0 software was used to create survival plots.

\section{Results}

During the study period, 200 consecutive patients (112 male, 88 female) underwent resection of GBM (55.5\% of patients underwent resection for a newly diagnosed GBM, whereas $44.5 \%$ of patients were operated on for a recurrent GBM). VE occurred in 53 patients (26.5\%) (Table 1). The average age was 58 years for the entire cohort with no difference between patients who had VE and those who did not (60 vs 56 years old, $\mathrm{p}=0.20$ ). The median preoperative Karnofsky Performance Scale (KPS) score was 90 for patients with and patients without VE. There was no difference in the percentage of $I D H$ wild-type tumors (84.9\% in patients with VE vs $84.4 \%$ in those without VE, $p=0.92$ ). There was no difference in the rates of chemotherapy and radiation therapy between the groups.

B

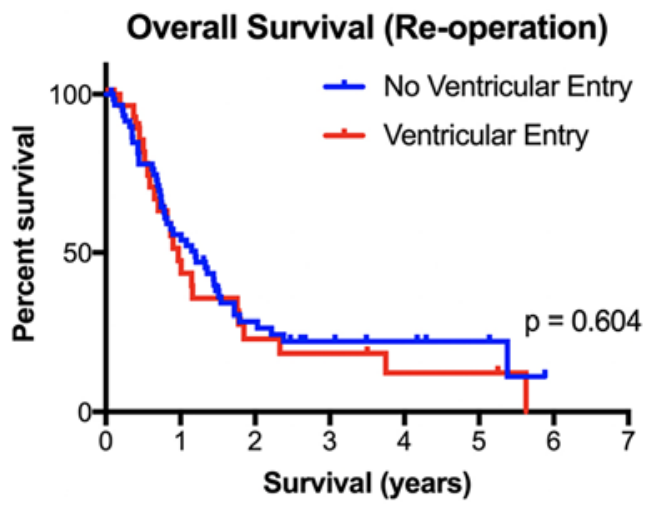

No. at Risk

$\begin{array}{lllllllll}\text { No Ventricular Entry } & 60 & 33 & 16 & 8 & 6 & 4 & 0 & 0\end{array}$ $\begin{array}{lllllllll}\text { Ventricular Entry } & 30 & 13 & 6 & 5 & 3 & 3 & 0 & 0\end{array}$

FIG. 3. Kaplan-Meier curves showing overall survival following VE in newly diagnosed and recurrent tumors undergoing resection. A: Trend toward worse survival in patients with VE compared to no VE $(p=0.08)$. B: No difference in survival from the time of repeat tumor resection for patients with VE compared to those without VE $(p=0.604)$. Figure is available in color online only. 


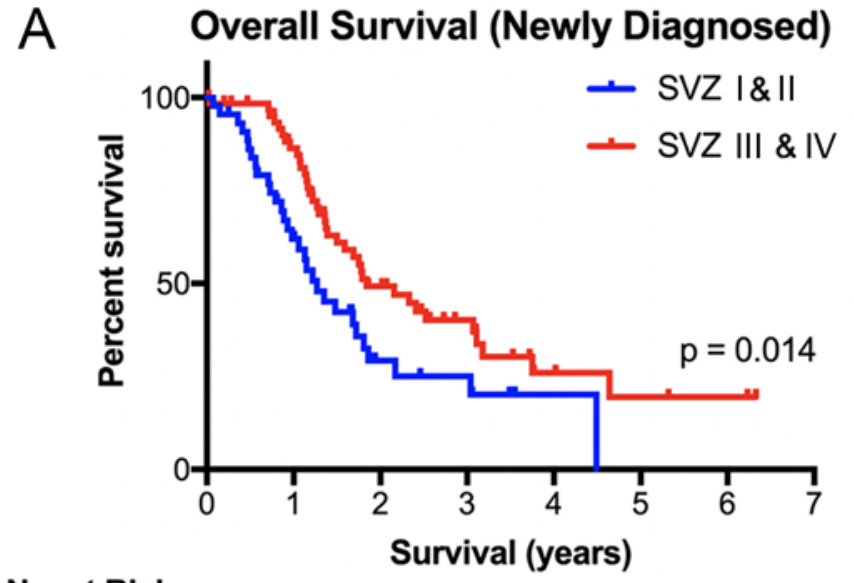

No. at Risk

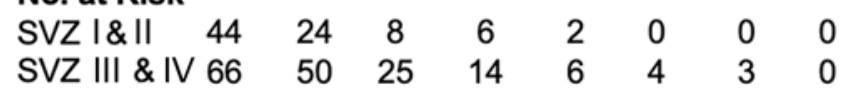
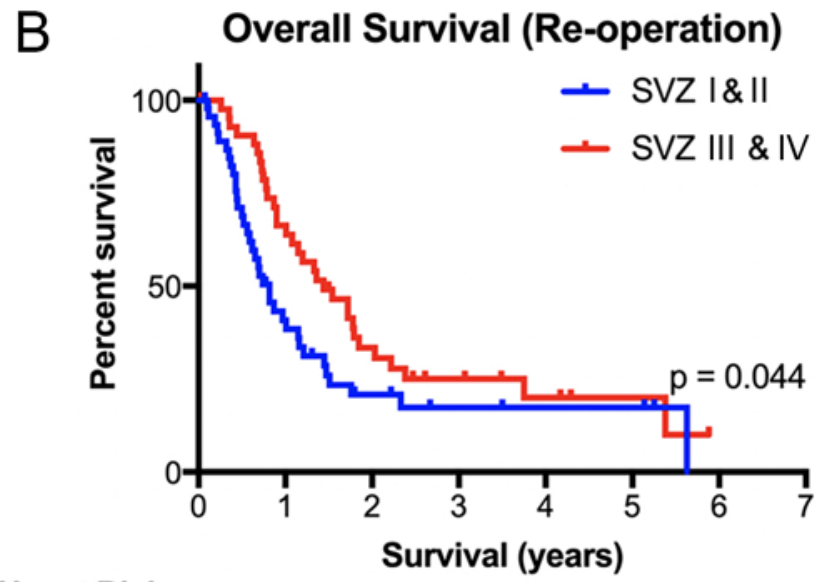

No. at Risk

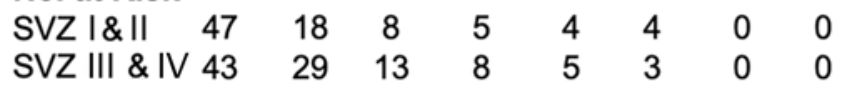

FIG. 4. Kaplan-Meier curves showing overall survival and SVZ location in newly diagnosed and recurrent tumors undergoing resection. Overall survival was worse in patients with SVZ type I and II tumors compared to SVZ type III and IV tumors at the time of first resection $(p=0.014)(A)$ and at the time of subsequent resection $(p=0.044)(B)$. Figure is available in color online only.

VE was slightly more common during repeat operations (56.6\% vs $40.1 \%, \mathrm{p}=0.039$ ). Patients who did not have VE went on to have future resections more frequently than patients who did have VE $(19.7 \%$ vs $7.5 \%, \mathrm{p}=0.051)$. Patients with VE were more likely to have preoperative subependymal involvement $(41.5 \%$ vs $15.0 \%, \mathrm{p}<0.001)$ and more likely to have SVZ type I tumors than patients without VE (66\% vs $29.3 \%$, p < 0.001). Initial tumor volumes were slightly larger for patients who had a VE during their surgical procedure compared to patients without $\mathrm{VE}$, although this did not reach statistical significance $(p=0.118)$.

The median length of stay was 3 days. The median postoperative KPS score was 80 for patients with and patients without VE. There was no difference in the rates of post-

\section{A}

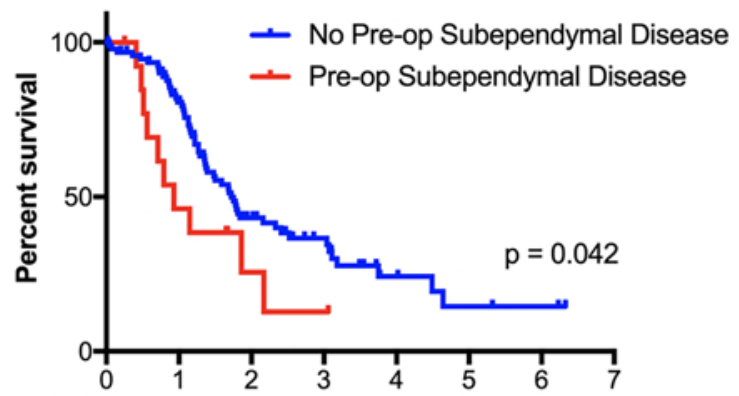

No. at Risk

Survival (years)

$\begin{array}{lllllllll}\text { No Sub. Disease } & 96 & 67 & 29 & 18 & 7 & 4 & 3 & 0\end{array}$

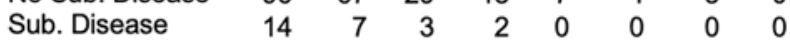

operative hydrocephalus, ventriculoperitoneal shunting, pseudomeningoceles, subdural hematomas, or wound infections between the patients who had VE and those without VE (Table 2). Only patients who had VE had an external ventricular drain placed in the resection cavity (i.e., cavity drain) postoperatively, and this was only done in 6 patients (11.3\%). Subdural hematomas occurred in both groups and none were symptomatic or required evacuation. There was no difference in the rates of intraventricular hemorrhage (1.9\% vs $1.4 \%, \mathrm{p}=0.787)$. Importantly, there was no difference in the rate of new leptomeningeal spread $(7.5 \%$ vs $10.2 \%, \mathrm{p}=0.572)$ or distant parenchymal recurrences $(17.0 \%$ vs $23.1 \%, \mathrm{p}=0.35)$ for patients with VE when compared to patients without VE.

B

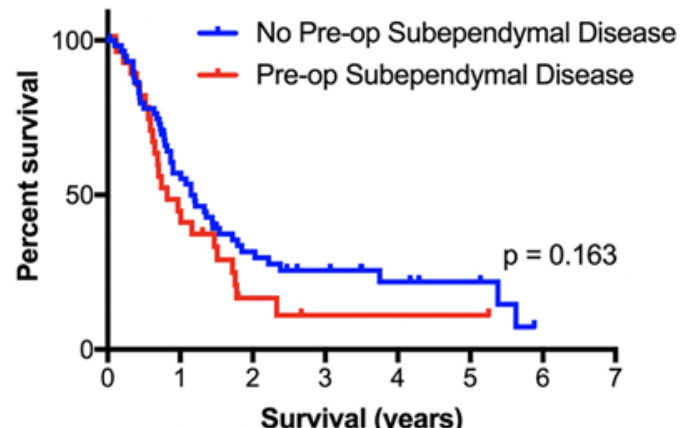

No. at Risk

$\begin{array}{lllllllll}\text { No Sub. Disease } & 60 & 34 & 17 & 11 & 7 & 5 & 0 & 0\end{array}$

$\begin{array}{lllllllll}\text { Sub. Disease } & 30 & 13 & 4 & 2 & 2 & 2 & 0 & 0\end{array}$

FIG. 5. Kaplan-Meier curves showing overall survival and subependymal disease in newly diagnosed and recurrent tumors undergoing resection. A: Overall survival was worse in patients with subependymal disease at the time of first resection $(p=0.042)$. B: There was no significant difference in overall survival at the time of repeat resection $(p=0.163)$. Sub. = subependymal. Figure is available in color online only. 
A Overall Survival - SVZ I \& II (Newly Diagnosed)

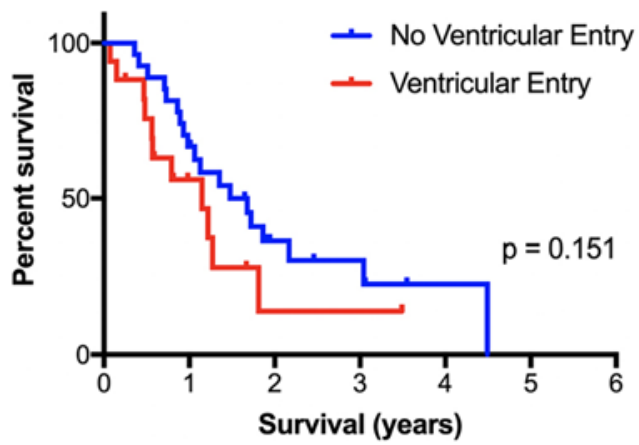

No. at Risk

$\begin{array}{lrrrrrrr}\text { No Ventricular Entry } & 27 & 18 & 7 & 5 & 2 & 0 & 0 \\ \text { Ventricular Entry } & 17 & 7 & 2 & 2 & 0 & 0 & 0\end{array}$

\section{No. at Risk}

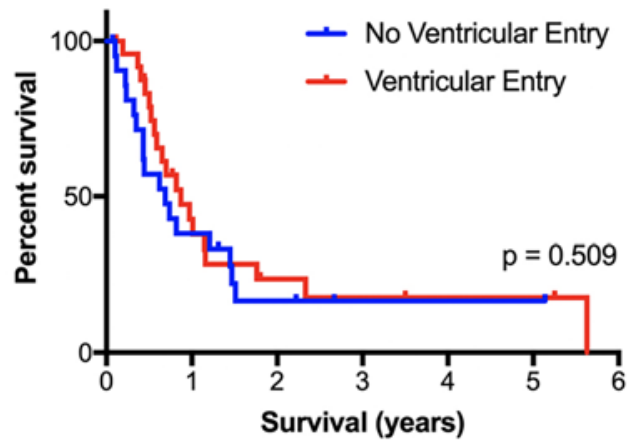

$\begin{array}{llllllll}\text { No Ventricular Entry } & 22 & 9 & 4 & 2 & 2 & 2 & 0\end{array}$ $\begin{array}{llllllll}\text { Ventricular Entry } & 25 & 10 & 5 & 4 & 3 & 3 & 0\end{array}$

FIG. 6. Kaplan-Meier curves showing overall survival and VE controlling for SVZ location in newly diagnosed and recurrent tumors undergoing resection. There was no difference in overall survival in patients with SVZ type I and II tumors with or without VE at time of first resection $(p=0.151)(A)$ or at repeat resection $(p=0.509)(B)$. Figure is available in color online only.

Based on volumetric analysis, the mean EOR for firsttime resections was $92.0 \%$. There was a correlation between SVZ type and EOR, but there was no effect of VE on EOR when controlling for SVZ type (Table 3).

The overall survival for patients undergoing first-time GBM resection with VE was 1.22 years compared to 1.75 years for patients without VE $(\mathrm{p}=0.08$, HR $0.59,95 \% \mathrm{CI}$ 0.29-1.21) (Fig. 3A). Patients with tumors that contacted the SVZ (type I or II tumors) had worse survival than patients whose tumors did not contact the SVZ (type III or IV tumors) (1.27 vs 1.84 years, $\mathrm{p}=0.014$, HR 1.8, 95\% CI 1.08-3.03) (Fig. 4A). Similarly, preoperative subependymal disease was associated with much worse survival (0.93 vs 1.72 years, $p=0.04$, HR $1.6,95 \%$ CI $1.00-2.62$ ) (Fig. 5A). When limiting the analysis to only patients with tumors that contacted the SVZ (type I or II), VE was not associated with worse survival (1.15 vs 1.68 years, $\mathrm{p}=$ 0.151 , HR 0.59, 95\% CI 0.26-1.34) (Fig. 6A). There was no relationship between VE, SVZ, or subependymal disease and survival for patients undergoing repeat tumor resections (Figs. 3-6, panel B). Accordingly, on univariate analysis only extensive subependymal disease predicted worse survival for patients undergoing first-time resection (Table 4). No variables were significant predictors of distant recurrence or leptomeningeal disease. On multivariate analysis, neither VE nor subependymal disease predicted overall survival, although subependymal disease trended toward significance (Table 5).

\section{Discussion}

Periventricular gliomas have been associated with worse prognosis compared to other locations..$^{3,11,13-15}$ There are several concerns with entry into the ventricular system. First, prior work has suggested that VE is associated with an increased incidence of leptomeningeal dissemination, possibly through CSF circulation of neoplastic cells. ${ }^{16,17}$ Second, prior reports have demonstrated that complication rates are increased with VE, with higher rates of postoperative hydrocephalus, intraventricular hemorrhage, and infection seen in this group. John et al. reported that nearly $50 \%$ of patients with VE during tumor resection suffered

TABLE 4. Univariate analysis for predictors of survival, leptomeningeal disease, and distant parenchymal recurrence for newly diagnosed patients

\begin{tabular}{|c|c|c|c|c|c|c|}
\hline \multirow[b]{2}{*}{ Outcome } & \multicolumn{3}{|c|}{ Overall Survival } & \multicolumn{3}{|c|}{ Leptomeningeal Disease/Distant Recurrence } \\
\hline & $p$ Value & $\mathrm{HR}$ & $95 \% \mathrm{Cl}$ & $p$ Value & OR & $95 \% \mathrm{Cl}$ \\
\hline \multicolumn{7}{|l|}{ SVZ } \\
\hline I & 0.320 & 1.842 & $0.553-6.135$ & 0.999 & $>10^{3}$ & NC \\
\hline II & 0.343 & 1.963 & $0.486-7.924$ & 0.999 & $>10^{3}$ & NC \\
\hline III & 0.976 & 1.018 & $0.311-3.338$ & 0.999 & $>10^{3}$ & NC \\
\hline IV & Reference & Reference & Reference & 0.959 & Reference & Reference \\
\hline VE & 0.083 & 1.718 & $0.931-3.171$ & 0.406 & 0.725 & $0.340-1.548$ \\
\hline Subependymal disease & 0.046 & 2.000 & $1.012-3.950$ & 0.694 & 1.164 & $0.546-2.484$ \\
\hline Tumor vol & 0.732 & 1.001 & $0.993-1.010$ & 0.488 & 1.004 & $0.992-1.017$ \\
\hline
\end{tabular}

NC $=$ not calculable.

Boldface type indicates statistical significance. 
TABLE 5. Multivariate analysis for predictors of survival in newly diagnosed patients

\begin{tabular}{lccc}
\hline \multicolumn{1}{c}{ Outcome } & $\mathrm{p}$ Value & $\mathrm{HR}$ & $95 \% \mathrm{Cl}$ \\
\hline VE & 0.134 & 1.608 & $0.864-2.990$ \\
\hline Subependymal disease & 0.075 & 1.870 & $0.939-3.724$ \\
\hline
\end{tabular}

from a complication. ${ }^{10}$ Finally, worse overall survival has been reported in patients who have undergone VE..$^{10,11}$ However, fear of VE may limit EOR and lead to less optimal resections for these already difficult lesions. Although prior reports demonstrate increased complication rates after VE, this has not been our experience, and we have not limited resection to avoid VE. We therefore examined outcomes at our institution to provide further clarification.

In this report we demonstrate that the complication rate is very low, and that it is similar for patients with and those without VE. Our observed rates of hydrocephalus, postoperative infection, subdural hematoma, and intraventricular hemorrhage were low and there was no significant difference noted between the two groups. Nevertheless, there was a trend toward an increased rate of postoperative subdural collections in the patients with VE, and a larger study with more power may detect this to be a significant difference. This differs from previously published series that found higher rates of these complications after VE. ${ }^{10,11}$ In our study, the rate of leptomeningeal dissemination or distant recurrence was similar between cohorts in our analysis, and it was within the range of what has been previously reported in multivariate analysis (Table 6). ${ }^{11}$

Interestingly, we also did not observe an increase in leptomeningeal disease or distant GBM recurrences in patients with preoperative subependymal disease. One possible explanation for this observation is the presence of parallel monoclonal expansions occurring in spatially distinct regions for patients with multifocal GBM, rather than spread or migration of tumor cells from a single site of origin - a theory supported by some genomic analyses. ${ }^{18}$

Although there was a trend toward worse survival for patients with VE in the univariate analysis, this was not the case when controlling for subependymal disease in the multivariate analysis. Thus, it appears that tumor location is the major factor influencing this observation of worse outcomes, and VE itself probably does not negatively impact patients. We did not observe a difference in EOR for patients with VE when controlling for SVZ type.

There are several reasons that overall survival may be worse in patients with subependymal disease spread. Gliomas that extend down to the periventricular region are at high risk of involving subcortical language or motor tracts that may limit safe resection. There is also a hypothesis that tumors in this region may intrinsically have higher proliferative or invasive capabilities, contributing to worse survival outcomes. ${ }^{19}$ As with gliomas in any location, extensive resection must be balanced with avoidance of postoperative neurological deficits that negatively impact function. ${ }^{2,20-22}$ Based on the results in this study, we believe that the consequences of VE are minimal, and we continue to advocate for VE during surgery if it assists in achieving a maximal EOR for periventricular gliomas.

This study does have limitations; it is a retrospective analysis from a high-volume single center. A study from multiple centers may provide more generalizable guidance on the impact of VE on outcomes for patients with GBM as well as provide a larger sample size that will improve our ability to detect any subtle effects of VE on these relatively rare complications. Groups were not randomized, and selection bias may impact comparability between groups, because some patients had tumors that were not approximating or near the ventricle. Additionally, CSF was not sampled following VE to determine if tumor cells were disseminated. Finally, the size of the VE was not quantified in this study; however, the VE was tailored to facilitate re-

TABLE 6. Summary of literature on the effects of VE

\begin{tabular}{|c|c|c|c|c|c|c|}
\hline $\begin{array}{l}\text { Authors } \\
\& \text { Year }\end{array}$ & $\begin{array}{l}\text { No. of } \\
\text { Patients } \\
\text { W/ VE }\end{array}$ & $\begin{array}{c}\text { Survival } \\
\text { (mos) }\end{array}$ & $\begin{array}{l}\text { Hydrocephalus } \\
\text { (VE vs no VE) }\end{array}$ & $\begin{array}{l}\text { Leptomeningeal } \\
\text { Dissemination } \\
\text { (VE vs no VE) }\end{array}$ & $\begin{array}{l}\text { Distant } \\
\text { Recurrence } \\
\text { (VE vs no VE) }\end{array}$ & Conclusion \\
\hline $\begin{array}{l}\text { Present } \\
\text { study }\end{array}$ & 53 & $\begin{array}{l}\text { Dependent } \\
\text { on SVZI } \\
\text { ependymal } \\
\text { disease }\end{array}$ & $1.9 \%$ vs $4.8 \%$ & $7.5 \%$ vs $10.2 \%$ & $17.0 \%$ vs $23.1 \%$ & $\begin{array}{l}\text { Surgical opening of ventricle is well tolerated \& does not } \\
\text { result in impaired patient survival when controlling for } \\
\text { tumor location. Surgeons should not fear entering the } \\
\text { ventricle \& should not view it as a barrier limiting tumor } \\
\text { resection. }\end{array}$ \\
\hline $\begin{array}{l}\text { Mistry et } \\
\text { al., 201912 }\end{array}$ & 85 & 15.1 vs 16.5 & $8.2 \%$ vs NR & $33.6 \%$ vs NR & $25.4 \%$ vs NR & $\begin{array}{l}\text { SVZ contact, \& not VE, is associated w/ postop hydro- } \\
\text { cephalus, leptomeningeal disease, \& worse survival. } \\
\text { VE had no effect on EOR. }\end{array}$ \\
\hline $\begin{array}{l}\text { Mistry et } \\
\text { al., 2018 }\end{array}$ & 422 & 16.8 vs 19.1 & $13.5 \%$ vs $1.9 \%$ & $21.0 \%$ vs $6.7 \%$ & NR & $\begin{array}{l}\text { Neurosurgeons \& neuro-oncologists should be aware } \\
\text { of the consequences of entering the ventricle during } \\
\text { surgery for HGG-namely tumor dissemination, } \\
\text { hydrocephalus, \& decreased survival. }\end{array}$ \\
\hline $\begin{array}{l}\text { John et } \\
\text { al., } 2017^{10}\end{array}$ & 35 & 11.0 vs 17.4 & $6 \%$ vs $0 \%$ & NR & NR & Complications are more frequent following VE. \\
\hline
\end{tabular}

HGG = high-grade glioma; NR = not reported.

${ }^{*}$ Meta-analysis of 20 studies. 
section of the tumor and, as a result, the opening in the ventricular lining was often small, which may limit the generalizability of these findings for patients who require very large openings into the ventricle. One interesting area of future investigation is the biological significance of FLAIR hyperintense signal near the ventricular wall, because there are likely to be tumor cells within this FLAIR signal. By restricting our grouping of tumors to the contrast-enhancing disease alone, a portion of the tumor mass is probably not being completely considered in this distinction.

\section{Conclusions}

The consequences of VE during GBM resection have been unclear prior to this study. However, we found that VE was well tolerated, with complications such as hydrocephalus, intraventricular hemorrhage, and surgical site infections being rare events. There was no difference in the rate of these complications between patients with VE and those without VE. Moreover, there was no increase in leptomeningeal spread or distant parenchymal recurrence in patients with VE. Finally, although survival was worse for patients with preoperative subependymal disease, VE did not change survival for patients with tumors contacting the ventricle. Therefore, if the goal of surgery is to maximize EOR, and VE is needed to achieve this goal, then there should be no contraindication to entering the ventricle, because we did not find any increase in adverse patient outcomes or tumor dissemination when this occurred.

\section{Acknowledgments}

Dr. Hervey-Jumper received financial support from the Robert Wood Johnson Foundation (74259), NINDS (K08 110919-01), and Loglio Collective.

\section{References}

1. Stupp R, Mason WP, van den Bent MJ, et al. Radiotherapy plus concomitant and adjuvant temozolomide for glioblastoma. N Engl J Med. 2005;352(10):987-996.

2. Molinaro AM, Hervey-Jumper S, Morshed RA, et al. Association of maximal extent of resection of contrast-enhanced and non-contrast-enhanced tumor with survival within molecular subgroups of patients with newly diagnosed glioblastoma. JAMA Oncol. 2020;6(4):495-503.

3. Awad AW, Karsy M, Sanai N, et al. Impact of removed tumor volume and location on patient outcome in glioblastoma. $J$ Neurooncol. 2017;135(1):161-171.

4. Chaichana KL, McGirt MJ, Frazier J, et al. Relationship of glioblastoma multiforme to the lateral ventricles predicts survival following tumor resection. J Neurooncol. 2008;89(2):219-224.

5. Jafri NF, Clarke JL, Weinberg V, et al. Relationship of glioblastoma multiforme to the subventricular zone is associated with survival. Neuro Oncol. 2013;15(1):91-96.

6. Mistry AM, Hale AT, Chambless LB, et al. Influence of glioblastoma contact with the lateral ventricle on survival: a meta-analysis. J Neurooncol. 2017;131(1):125-133.

7. Lim DA, Cha S, Mayo MC, et al. Relationship of glioblastoma multiforme to neural stem cell regions predicts invasive and multifocal tumor phenotype. Neuro Oncol. 2007;9(4):424-429.

8. Sanai N, Tramontin AD, Quiñones-Hinojosa A, et al. Unique astrocyte ribbon in adult human brain contains neural stem cells but lacks chain migration. Nature. 2004;427(6976):740-744.

9. Sanai N, Alvarez-Buylla A, Berger MS. Neural stem cells and the origin of gliomas. N Engl J Med. 2005;353(8):811-822.
10. John JK, Robin AM, Pabaney AH, et al. Complications of ventricular entry during craniotomy for brain tumor resection. J Neurosurg. 2017;127(2):426-432.

11. Mistry AM, Kelly PD, Thompson RC, Chambless LB. Cancer dissemination, hydrocephalus, and survival after cerebral ventricular entry during high-grade glioma surgery: a metaanalysis. Neurosurgery. 2018;83(6):1119-1127.

12. Mistry AM, Kelly PD, Gallant JN, et al. Comparative analysis of subventricular zone glioblastoma contact and ventricular entry during resection in predicting dissemination, hydrocephalus, and survival. Neurosurgery. 2019;85(5):E924-E932.

13. Chaichana KL, Pendleton C, Chambless L, et al. Multi-institutional validation of a preoperative scoring system which predicts survival for patients with glioblastoma. J Clin Neurosci. 2013;20(10):1422-1426.

14. Chaichana K, Parker S, Olivi A, Quiñones-Hinojosa A. A proposed classification system that projects outcomes based on preoperative variables for adult patients with glioblastoma multiforme. J Neurosurg. 2010;112(5):997-1004.

15. Yang W, Xu T, Garzon-Muvdi T, et al. Survival of ventricular and periventricular high-grade gliomas: a surveillance, epidemiology, and end results program-based study. World Neurosurg. 2018;111:e323-e334.

16. Elliott JP, Keles GE, Waite M, et al. Ventricular entry during resection of malignant gliomas: effect on intracranial cerebrospinal fluid tumor dissemination. J Neurosurg. 1994;80(5):834-839.

17. Grabb PA, Albright AL, Pang D. Dissemination of supratentorial malignant gliomas via the cerebrospinal fluid in children. Neurosurgery. 1992;30(1):64-71.

18. Abou-El-Ardat K, Seifert M, Becker K, et al. Comprehensive molecular characterization of multifocal glioblastoma proves its monoclonal origin and reveals novel insights into clonal evolution and heterogeneity of glioblastomas. Neuro Oncol. 2017;19(4):546-557.

19. Quiñones-Hinojosa A, Chaichana K. The human subventricular zone: a source of new cells and a potential source of brain tumors. Exp Neurol. 2007;205(2):313-324.

20. Stummer W, Reulen HJ, Meinel T, et al. Extent of resection and survival in glioblastoma multiforme: identification of and adjustment for bias. Neurosurgery. 2008;62(3):564-576.

21. McGirt MJ, Mukherjee D, Chaichana KL, et al. Association of surgically acquired motor and language deficits on overall survival after resection of glioblastoma multiforme. Neurosurgery. 2009;65(3):463-470.

22. Patel CK, Vemaraju R, Glasbey J, et al. Trends in peri-operative performance status following resection of high grade glioma and brain metastases: the impact on survival. Clin Neurol Neurosurg. 2018;164:67-71.

\section{Disclosures}

The authors report no conflict of interest concerning the materials or methods used in this study or the findings specified in this paper.

\section{Author Contributions}

Conception and design: Berger, Young, Gogos, Hervey-Jumper. Acquisition of data: Young, Gogos, Pereira, Morshed, Li, Barkovich. Analysis and interpretation of data: Young, Gogos, Morshed. Drafting the article: Berger, Young, Gogos, Morshed. Critically revising the article: all authors. Reviewed submitted version of manuscript: all authors. Approved the final version of the manuscript on behalf of all authors: Berger. Statistical analysis: Young, Gogos, Pereira, Li. Administrative/technical/ material support: Berger. Study supervision: Berger.

\section{Correspondence}

Mitchel S. Berger: University of California, San Francisco, CA. mitchel.berger@ucsf.edu. 